\title{
Clinical potential of angiogenic therapy and cellular reprogramming
}

\author{
Christopher T. Ryan, MD, Vivek Patel, MD, and Todd K. Rosengart, MD
}

Feature Editor Note-You're driving along the freeway during rush hour. You're running late and find yourself in bumper-to-bumper traffic. You have 3 options: (1) do nothing, suffer with anguish inside; (2) find productive ways to pass the time, like listen to a podcast or talk on the phone; or (3) get off on the next exit and find an alternative, roundabout path to your destination. Similarly, patients suffering from coronary artery disease can opt to do nothing; stop progression and treat their symptoms with medical therapy; or undergo revascularization either percutaneously or surgically.

There are few options, however, for those who develop chronic coronary artery disease without suitable revascularization strategies. They have missed their exit and are stuck in this metaphorical traffic jam, with no radio and no cell phone. These patients may experience refractory angina or develop ischemic cardiomyopathy and heart failure. Exploring solutions to this increasingly widespread problem is imperative. Chronic heart failure is rising, while the number of organs available for transplantation remains limited. Similarly, bridge therapies such as ventricular assist devices are resource intensive and are typically only performed at select, high-volume institutions.

In the following article, the authors explore cardiac regenerative strategies to bridge this therapeutic gap. They delve into a so-called "biologic bypass," which aims to restore perfusion and functionality of ischemic myocardium. Specifically, they review published preclinical data and the potential clinical implementation of cardiac reprogramming of fibrotic tissue into functioning, contractile myocardium, as well as angiogenic therapies aimed at inducing angiogenesis. These innovative and forward-thinking approaches will be

From the Division of Cardiothoracic Surgery, Michael E. DeBakey Department of Surgery, Baylor College of Medicine, Houston, Tex.

Dr Ryan is supported by the National Institutes of Health/National Heart, Lung, and Blood Institute Research Training Program in Cardiovascular Surgery (T32 HL139430). Dr Rosengart is supported by a grant from the National Institutes of Health/National Heart, Lung, and Blood Institute (1R01HL152280-01).

Received for publication Dec 14, 2020; accepted for publication Dec 14, 2020; available ahead of print April 7, 2021

Address for reprints: Todd K. Rosengart, MD, Michael E. DeBakey Department of Surgery, One Baylor Plaza, MC 390, Houston, TX 77030 (E-mail: Todd. Rosengart@bcm.edu).

JTCVS Open 2021;6:108-15

2666-2736

Copyright $(C) 2021$ The Author(s). Published by Elsevier Inc. on behalf of The American Association for Thoracic Surgery. This is an open access article under the CC BY-NC-ND license (http://creativecommons.org/licenses/by-nc-nd/4.0/).

https://doi.org/10.1016/j.xjon.2020.12.023

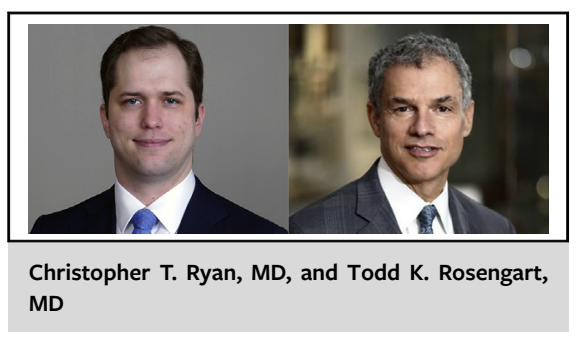

CENTRAL MESSAGE

Angiogenesis and cellular reprogramming are promising cardiac regenerative therapies for refractory angina and ischemic cardiomyopathy.

See Commentaries on pages 116 and 118.

necessary to combat the challenges faced by the heart specialists of tomorrow.

\section{Jordan Dozier, MD, and Nahush A. Mokadam, MD}

Despite advancements in medical and interventional therapy, myocardial infarction (MI) and heart failure (HF) resulting from coronary artery disease (CAD) remain the leading causes of death worldwide. ${ }^{1}$ Severe CAD frequently manifests as a chronic condition featuring progressive myocardial damage from successive ischemic insults, with efforts to reverse damage and restore function hindered by the limited regenerative capacity of adult myocardium. ${ }^{1-3}$ Limitations in therapeutic options for patients with severe CAD have prompted extensive preclinical investigations into cardiac regenerative strategies.

Direct cellular reprogramming and therapeutic angiogenesis are 2 promising regenerative strategies with potential applications for patients with chronic CAD. Direct cellular reprogramming is the conversion of cellular identity from one differentiated state to another, without requiring an intermediate pluripotent state. ${ }^{4}$ This technique has been used to convert stromal cells in diseased tissue into specialized cells including neurons, pancreatic cells, or cardiomyocytes to restore organ function. ${ }^{4}$ Direct cardiac cellular reprogramming involves in situ conversion of cardiac fibroblasts into induced cardiomyocytes (iCMs) to restore contractile cell populations. ${ }^{5,6}$ This direct reprogramming approach differs from exogenous stem cell therapies, including the 
delivery of induced pluripotent stem or other stem cells, which attempt to implant these exogenous cells into regions of damaged myocardium (Figure 1). These exogenous implantation efforts have largely failed to achieve clinically significant benefits despite decades of exhaustive research. ${ }^{7}$

Angiogenic therapy involves delivery of genes or growth factors to induce formation of new collateral vessels and restore perfusion to ischemic tissue. The majority of translational research in angiogenic therapy has focused on patients with chronic CAD or peripheral artery disease, although the field has grown to include applications in chronic wound healing and reconstructive surgery. ${ }^{8-11}$ For patients with myocardial ischemia, angiogenic therapy may provide a "biologic bypass" to restore perfusion to ischemic myocardium when other revascularization options are not feasible.

In this article, we describe potential clinical applications of cardiac reprogramming and angiogenic therapy, summarize recent breakthroughs in the field, and outline future steps necessary to realize the clinical potential of these therapies.

\section{TARGET PATIENT POPULATIONS AND CURRENT THERAPEUTIC GAPS \\ Advanced HF}

The prevalence of chronic HF is $\sim 1.2 \%$ to $4.2 \%$ in developed countries, and the number of patients with HF continues increasing due to improved survival after acute MI, population aging, and increased prevalence of obesity, diabetes, and hypertension. ${ }^{12,13}$ Newly diagnosed HF portends a 5-fold increase in annual mortality risk, and deaths attributable to HF increased by $38 \%$ in the United States between 2011 and 2017. ${ }^{12,14}$ Ischemic heart disease remains a major driver of incident HF, and the adult myocardium is largely incapable of replacing lost cardiomyocytes. ${ }^{2,3} \mathrm{Cur}-$ rent therapy focuses primarily on managing symptoms and limiting ongoing myocardial damage. ${ }^{2}$

Patients progressing to severe HF, typically defined as severe symptoms with functional impairment and recurrent hospitalizations despite optimal medical therapy, have few options beyond organ transplantation or left ventricular assist devices. ${ }^{15,16}$ Heart transplantation remains limited by a shortage of donor organs and the requirement for lifelong immunosuppresion, whereas left ventricular assist device therapy is associated with significant morbidity, including stroke, infection, and right ventricular failure. ${ }^{15,16}$ In addition, many patients are ineligible for these therapies due to comorbidities or advanced age.

This therapeutic gap has been the focus of intense research efforts, beginning with the enthusiastic pursuit of stem cell therapy as a means of regenerating damaged myocardium. The initial hypothesis for stem cell therapy

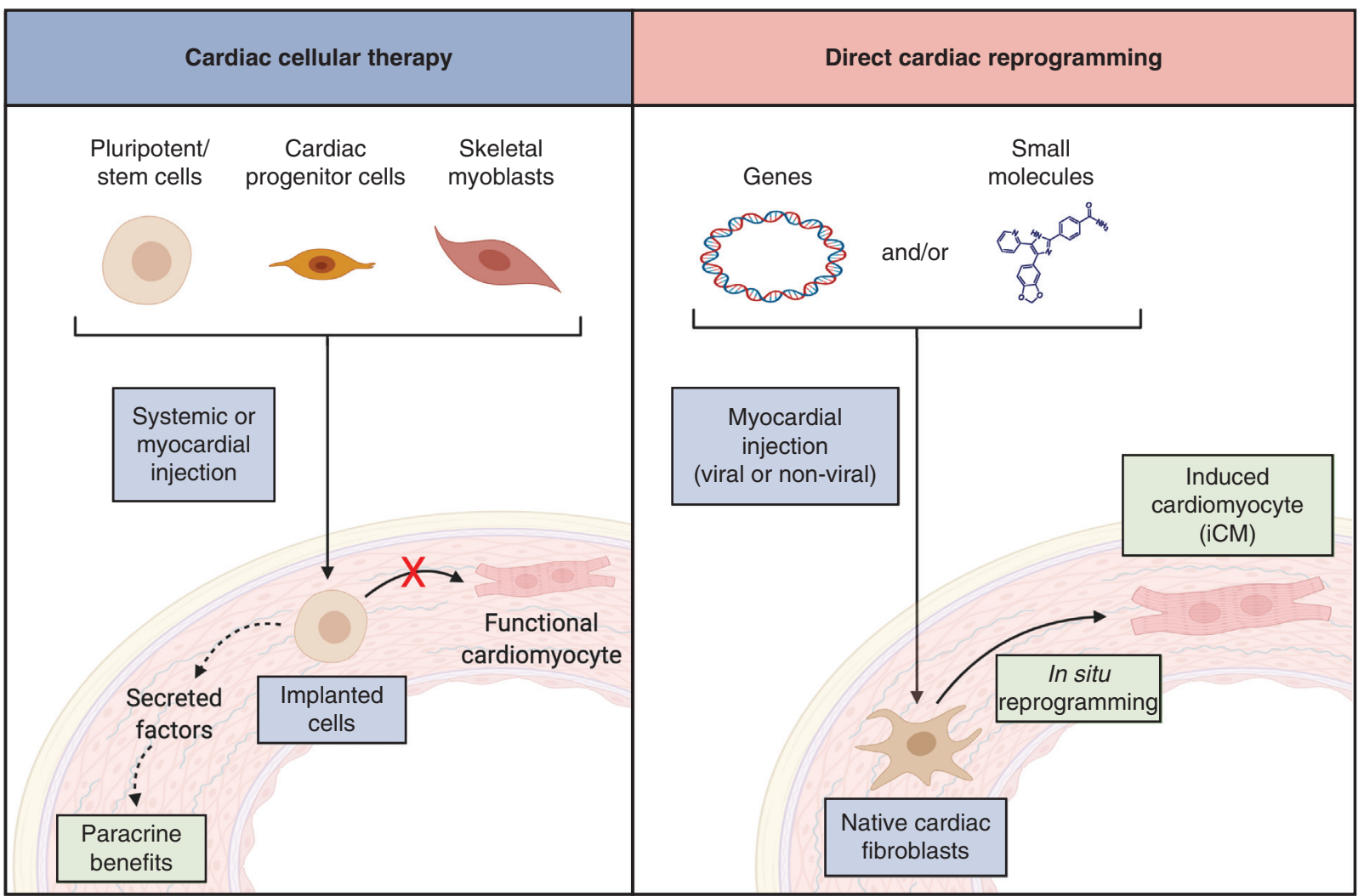

FIGURE 1. Therapeutic approach for cardiac cellular therapy versus cardiac reprogramming. Cardiac cellular therapy (left panel) introduces exogenous cells, which are largely incapable of differentiation to cardiomyocytes but may exert beneficial paracrine effects. Direct cardiac reprogramming (right panel) introduces exogenous genes or small molecules to native cardiac fibroblasts and induces in situ transdifferentiation into new contractile cells. 
was that injected stem cells would differentiate into new cardiomyocytes. ${ }^{17}$ However, extensive preclinical research has since demonstrated that few exogenous cells survive in the myocardium after injection and that surviving cells rarely differentiate into cardiomyocytes. ${ }^{18-20}$ Benefits ascribed to cell therapy in animal models are instead thought to derive from paracrine effects of implanted cells on postischemic myocardium, including prosurvival, angiogenic, and immune-modulatory effects (Figure 1). ${ }^{19,20}$

Initial, phase 1 stem cell trials appeared to support the efficacy of the cell therapy approach but were plagued by small sample sizes, methodologic limitations, and an over-reliance on surrogate outcome measures. ${ }^{21}$ Subsequent randomized, placebo-controlled trials have cumulatively enrolled thousands of patients and used a variety of cell types with disappointing results, demonstrating no benefit on hard outcomes and clinically insignificant improvements in ejection fraction $(0.0 \%-5.4 \%))^{7}$ Many investigators have turned toward alternative cardiac regenerative strategies as a more promising approach to address the growing HF epidemic. ${ }^{22-24}$

\section{Angina Refractory to Conventional Therapy}

Another potential application of biological therapy is "no-option" angina, strictly defined as severe, life-limiting angina due to $\mathrm{CAD}$, refractory to maximal medical therapy, and without surgical or percutaneous revascularization options. ${ }^{25,26}$ Coronary insufficiency in these patients is attributed to coronary artery stenosis on angiography and/or microvascular dysfunction. ${ }^{25,27}$ The incidence of nonrevascularizable angina in the United States is $\sim 50,000$ to 200,000 patients/year, although it is difficult to estimate how many would meet the strict inclusion criteria used in clinical trials. $^{28-30}$

Many other patients with multivessel CAD may be amenable to surgical or percutaneous revascularization but cannot be fully revascularized for technical or anatomic reasons. Incomplete revascularization of 1 or more myocardial territories occurs in $10 \%$ to $37 \%$ of patients after coronary artery bypass grafting and is associated with an increased risk for postoperative angina (odds ratio [OR], $1.71 ; 95 \%$ confidence interval [CI], 1.08-2.70), major adverse cardiac events (OR, 2.27; 95\% CI, 1.72-3.03), and mortality (OR, $1.43 ; 95 \%$ CI, 1.25-1.61). ${ }^{31-34}$ Overall, the prevalence of nonrevascularizable myocardial ischemia is projected to steadily increase. ${ }^{29,35}$ The growing therapeutic gap for no-option angina requires alternative treatment strategies.

\section{Recent Developments in Cardiac Reprogramming}

Cardiac reprogramming has the potential to restore function by transitioning the expanded fibroblast population within postischemic myocardium into new contractile cells. In postinfarct rodent models, intramyocardial injection of viral vectors overexpressing the original GMT (Gata4, $M e f 2 c$, and $T b \times 5)$ transcription factor cocktail significantly improves ventricular function and reduces myocardial fibrosis. ${ }^{36}$ Functional recovery in postinfarction murine models suggests cardiac reprogramming has tremendous clinical potential. However, clinical translation will require overcoming important challenges, including the low efficiency of reprogramming in human cells, an immature cardiomyocyte phenotype of reprogrammed cells, and incomplete resolution of inflammatory signaling and the fibroblast gene program. ${ }^{37,38}$

Increasing the reprogramming efficiency in human cardiac fibroblasts, assessed by the percentage of treated cells expressing cardiomyocyte markers, has been a major focus in the field of cardiac reprogramming. The GMT transcription cocktail effectively reprograms murine fibroblasts into iCMs but does not result in appreciable reprogramming in human cardiac fibroblasts. ${ }^{39}$ Early reports of successful human cardiac reprogramming used 7 or more transcription factors yet only achieved a fraction of the reprogramming efficiency obtained in murine cells with the 3 -factor GMT cocktail. ${ }^{39,40}$

Continuing to increase the number of transcription factors is unlikely to be a successful strategy, for 2 primary reasons. First, the number of factors that gene therapy vectors can deliver is inherently limited by the size of the vector's gene expression cassette. ${ }^{41}$ More importantly, each additional factor theoretically increases the chance of unintended, harmful effects. The optimal reprogramming cocktail for human use will achieve efficient reprogramming with the fewest possible factors to maximize efficacy and maintain an acceptable risk profile.

As an alternative to the continued expansion of the number of transcription factors, several groups have reported adjunctive agents that improve cardiac reprogramming efficiency in murine and human cells. Much of this work focuses on growth factors or small molecules targeting receptors and/or intracellular signaling pathways., ${ }^{62-45}$ Small molecules are particularly useful for suppressing profibrotic and inflammatory pathways during cardiac reprogramming, and significantly improved in vitro reprogramming efficiency is achieved with inhibitors of transforming growth factor- $\beta$, Rho-associated kinase, prostaglandin, and interleukin- $1 \beta$ signaling. ${ }^{42,44-46}$ Importantly, Mohamed and colleagues ${ }^{44}$ demonstrated small molecules also improve the in vivo efficacy of cardiac reprogramming. Anti-inflammatory strategies could be particularly important for cardiac reprogramming in chronic HF, given the persistent myocardial inflammation in this condition. ${ }^{47}$

Increased resistance to reprogramming in human cardiac fibroblasts appears to be due, in part, to additional epigenetic barriers that are absent in lower-order mammals. ${ }^{37,38,48}$ Because the epigenetic state of differentiated cells acts to resist changes in cell phenotype by restricting gene expression, reshaping this epigenetic background is 
essential to successful reprogramming. ${ }^{49,50}$ While transcription factors can partially modify the epigenetic state by influencing chromatin-modifying enzymes, several groups have reported strategies to directly alter the epigenetic state to facilitate more efficient cardiac reprogramming. ${ }^{46,49,51-53}$ Chemical inhibition of histone deacetylases, enzymes that induce a repressive epigenetic state, can greatly improve in vitro cardiac reprogramming efficiency in murine or human cells. ${ }^{46,51,52}$ However, these drugs are nonspecific and may have unintended, pleiotropic effects in reprogrammed and bystander cells. ${ }^{54,55}$

A more targeted approach is the inhibition of endogenous regulators of chromatin-modifying enzymes. Zhou and colleagues $^{53}$ identified the chromatin remodeling enzyme BMI1 as a key factor that recruits repressive epigenetic enzymes to cardiogenic genes. Knockdown of BMI1 permitted an open chromatin state and accelerated the adoption of a cardiomyocyte phenotype in mouse fibroblasts. It is presumed that BMI1 knockdown will also facilitate human reprogramming because BMI1 is highly conserved in structure and function, although this has not been directly investigated.

Our laboratory reported p63, the p53 family member, also plays a significant role in the epigenetic repression of cardiac gene expression in both murine and human cardiac fibroblasts. ${ }^{37,48}$ Knockdown of p63 to release epigenetic repression of cardiomyocyte genes can significantly improve in vitro cardiac reprogramming efficiency and may be an essential component of optimized cocktails for human cardiac reprogramming. ${ }^{37,48}$ Presumably, derepression of epigenetic barriers will also enhance in vivo reprogramming, although this has not been demonstrated to date. Importantly, in vitro experiments suggest that epigenetic barriers to cardiac reprogramming are similar in human and porcine cells, supporting pigs as an appropriate preclinical large animal model for future in vivo efficacy studies. $^{48}$

A promising development from murine MI models is the observation that treatment with GMT-based reprogramming cocktails produces a $\sim 50 \%$ reduction in fibrosis. ${ }^{56-58}$ Although a modest reduction in fibrosis could be attributed to reductions in the total fibroblast population due to conversion to iCMs, a $50 \%$ reduction in fibrosis is out of proportion to the number of iCMs created and suggests independent antifibrotic effect(s). Indeed, our laboratory has identified the transcription factor Gata4 as primarily responsible for the observed antifibrotic effect through down-regulation of the profibrotic mediator Snail and extracellular matrix proteins. ${ }^{56}$ While Gata4 alone cannot transdifferentiate fibroblasts into iCMs, Gata4 administration in murine MI models reduces fibrosis to an extent comparable with the full GMT cocktail. ${ }^{56}$ Cardiac reprogramming cocktails containing Gata4 could reduce fibrosis in addition to producing new contractile cells, a synergistic effect that would increase the clinical utility of this therapy.

\section{Next Steps for Clinical Translation of Cardiac Reprogramming}

Testing the therapeutic effects of cardiac reprogramming in large animal models represents the next major step toward clinical translation. Compared with rodents, large animals are better suited for evaluating potential therapeutic effects in humans due to their similarities in cardiac structure and workload. ${ }^{59}$ Large animal efficacy is particularly important for cardiac reprogramming, given the epigenetic barriers to cellular reprogramming in higher-order mammals. To evaluate potential therapeutic efficacy in patients with ischemic cardiomyopathy, our laboratory typically uses a chronic MI model with therapy delivered 4 weeks or longer after coronary artery ligation. Large-animal studies will ideally use a similar approach, or alternative models such as chronic pacing or microinfarct HF models, to assess the effectiveness of cardiac reprogramming in scarred myocardium present in patients with HF. ${ }^{60-62}$

In addition to testing transcription factor cocktails, largeanimal studies will need to determine the optimal viral vector for cardiac reprogramming. Many in vivo cardiac reprogramming studies have used integrating viral vectors (retrovirus or lentivirus), which have limited clinical utility due to the risk of insertional mutagenesis. ${ }^{63}$ Several nonintegrative viral vectors have been used successfully for cardiac reprogramming in small-animal models, including adenovirus, adeno-associated viruses, and the Sendai virus. ${ }^{36,57,64}$ However, these vectors have not been directly compared for cardiac reprogramming and have important differences in the persistence of gene expression, specificity of viral infection, and degree of host immune response. ${ }^{65,66}$ The choice of viral vector is a key factor for all gene therapy applications and will be a critical consideration for successful clinical applications of cardiac reprogramming.

\section{Recent Developments in Angiogenic Therapy}

In patients with severe $C A D$, perfusion of viable myocardium is critically dependent on collateral circulation. ${ }^{67}$ Tissue hypoxia and shear stress from altered coronary blood flow distal to acute or chronic coronary obstruction prompt the expansion of the collateral circulation as a protective response, resulting in partial restoration of perfusion distal to the culprit lesion. ${ }^{68}$ However, the extent of collateralization varies considerably between patients and is frequently insufficient to maintain adequate blood flow. ${ }^{67-69} \mathrm{~A}$ promising strategy to enhance collateralization in ischemic myocardium is using biological therapy to induce angiogenesis, the growth of new branches from existing vessels. ${ }^{11}$

The majority of clinical investigations have used the fibroblast growth factor or vascular endothelial growth 
factor (VEGF) family of peptides, as these factors play a central role in endogenous angiogenesis. In preclinical models, VEGF gene transfer significantly increases blood vessel density and collateral blood flow. ${ }^{11}$ Early-stage clinical trials of VEGF gene transfer in patients with nonrevascularizable, severe CAD, and/or severe angina have demonstrated a favorable safety profile, with several trials demonstrating improvements in myocardial perfusion and anginal symptoms. ${ }^{11,70}$ However, there was significant heterogeneity between trials, including critical differences in method of administration and vectors used for gene transfer. Experience gained from these initial trials and additional preclinical research has greatly increased our understanding of gene therapy pharmacokinetics and the biological mechanisms of angiogenesis. Applying this knowledge to optimize the next generation of VEGF therapy will greatly increase its clinical potential.

Many early trials used naked plasmids for gene transfer, a technique with extremely low transduction efficiency compared with viral vectors. ${ }^{11,22,71}$ In addition, many trials used simple intracoronary infusion, a method limited by atherosclerosis in native coronary vessels, poor endothelial penetrance of vectors, and "washout" of the virus into systemic circulation by ongoing coronary blood flow. ${ }^{11,72}$ Taken together, results in trials using plasmid vectors and/or simple coronary infusion are unlikely to reflect the true clinical potential of angiogenic therapy.

In contrast, intramyocardial injection of viral vectors achieves significant levels of local expression. ${ }^{73,74}$ Intramyocardial injection can be accomplished by direct epicardial injection through minimally invasive thoracotomy or percutaneously using catheter-based, transendocardial injection guided by electroanatomical mapping. ${ }^{75}$ Epicardial injection is generally considered the most reliable method, as surgical exposure allows visualization of target myocardium and epicardial vessels to ensure accurate and safe needle placement. ${ }^{76}$ However, this procedure is more invasive than catheter-based methods and poses potential risks from general anesthesia or damage to existing coronary artery bypass grafts. Finally, catheter-based transendocardial injection minimizes morbidity and provides access to the septal myocardium, which is not surgically accessible but requires highly specialized equipment with a significant learning curve. ${ }^{76,77}$

For both direct and catheter-based myocardial injection, theoretical concerns exist regarding potential myocardial damage from repeated needle insertions and resulting inflammation. ${ }^{78}$ These concerns arise largely from histologic evidence of needle track fibrosis in small-animal models. ${ }^{78}$ However, the size of the needle relative to the heart is much smaller in humans than rodents, and any injured myocardium is likely to be a small portion of the local myocardial mass. In addition, numerous clinical trials over 2 decades have demonstrated a uniformly favorable safety profile for these techniques. ${ }^{70,79-82}$

Continued preclinical research has also advanced our understanding of the molecular mechanisms of angiogenesis to further refine therapeutic applications of the $V E G F$ gene family. The VEGF-A gene undergoes extensive alternative splicing, forming multiple isoforms with distinct biological properties. ${ }^{83}$ Clinical trials to date have administered only a single VEGF-A isoform. ${ }^{11,70}$ However, simultaneous administration of the 3 major isoforms (VEGF-121, -165 , and -189) produces a synergistic effect, greatly increasing the in vivo angiogenic response compared with a single isoform. ${ }^{83}$ The efficacy and safety of VEGF administration is further enhanced by encoding all 3 major isoforms in a single viral vector and modifying the introns to optimize the ratio of isoform expression. ${ }^{84}$ An optimized VEGF transgene carried by a replication-deficient adenovirus vector and delivered by epicardial injection is currently being evaluated in a phase $1 / 2$, open-label, single-arm dose-escalation trial for no-option angina patients (EXACT trial [Epicardial Delivery of XC001 Gene Therapy for Refractory Angina Coronary Treatment]; http://www. clinicaltrials.gov; unique identifier: NCT04125732).

Although VEGF-A is used most frequently for angiogenic therapy, the VEGF-D isoform has also shown promise and produces angiogenic effects comparable with single VEGF-A isoforms. ${ }^{85}$ The laboratory of Seppo Ylä-Herttuala has developed variants of the mature form of VEGF$\mathrm{D}\left(\mathrm{VEGF}-\mathrm{D}^{\Delta \mathrm{N} \Delta \mathrm{C}}\right.$ ) with increased protein stability and receptor binding affinity. ${ }^{86,87}$ Intramyocardial injection of an adenoviral vector overexpressing VEGF-D $^{\Delta \mathrm{N} \Delta \mathrm{C}}$ improved myocardial perfusion in a preliminary trial, and clinical efficacy for no-option angina will be evaluated in an upcoming phase 2, randomized controlled trial (ReGenHeart trial [Adenovirus Vascular Endothelial Growth Factor D \{AdvVEGF-D \} Therapy for Treatment of Refractory Angina Pectoris]; http://www.clinicaltrials.gov; unique identifier: NCT03039751). ${ }^{88}$

\section{Synergism Between Cardiac Reprogramming and Angiogenic Therapy}

We have discussed HF and refractory angina as separate entities, but there is substantial overlap in clinical practice. Clinical HF is diagnosed in $26 \%$ to $33 \%$ of patients with refractory angina, and $32 \%$ of patients with advanced HF report significant angina. ${ }^{26,89,90}$ This large segment of patients could benefit from a strategy that both induces angiogenesis to improve regional perfusion and uses cardiac reprogramming to restore contractile cells.

Intriguingly, VEGF administration has been shown to improve the efficiency of the GMT cocktail for cardiac reprogramming. ${ }^{43,91}$ Adding recombinant VEGF to murine fibroblasts in vitro significantly increases the number of beating iCMs induced by treatment with the GMT 
transcription factor cocktail. ${ }^{43}$ In addition, pretreatment of ischemic myocardium with VEGF therapy in murine MI models increases the in vivo reprogramming efficiency of GMT injection, with greater recovery of myocardial function and decreased fibrosis compared with GMT alone. ${ }^{91}$ A combination therapy that addresses both coronary insufficiency and contractile failure in a single administration would be an invaluable tool for severe CAD, and additional research is ongoing to optimize the interaction between angiogenic and cardiac reprogramming therapy.

\section{CONCLUSIONS}

As the number of patients living with chronic, severe CAD continues to grow, new treatment strategies are needed to reduce morbidity and mortality in this difficultto-treat patient population. Cardiac reprogramming and angiogenic therapy have significant clinical potential to restore perfusion and contractile function to affected myocardium. By incorporating lessons from previous clinical trials and ongoing preclinical research, investigators continue to move biological therapy toward clinical application.

\section{Conflict of Interest Statement}

Dr Rosengart has previously received grant support from XyloCor Therapeutics, Inc, which is conducting the EXACT trial noted in the manuscript; is a coinventor on United States Patents (10,383,916; 6,518,255; 6,329,348) related to therapeutic angiogenesis; and has an ownership interest in XyloCor Therapeutics, Inc. All other authors reported no conflicts of interest.

The Journal policy requires editors and reviewers to disclose conflicts of interest and to decline handling or reviewing manuscripts for which they may have a conflict of interest. The editors and reviewers of this article have no conflicts of interest.

Figures were created using BioRender.com.

\section{References}

1. Benjamin EJ, Virani SS, Callaway CW, Chamberlain AM, Chang AR, Cheng S, et al. Heart disease and stroke statistics-2018 update: a report from the American Heart Association. Circulation. 2018;137:e67-492.

2. Elgendy IY, Mahtta D, Pepine CJ. Medical therapy for heart failure caused by ischemic heart disease. Circ Res. 2019;124:1520-35.

3. Bergmann O, Zdunek S, Felker A, Salehpour M, Alkass K, Bernard S, et al. Dynamics of cell generation and turnover in the human heart. Cell. 2015;161: 1566-75.

4. Srivastava D, DeWitt N. In vivo cellular reprogramming: the next generation. Cell. 2016;166:1386-96.

5. Ieda M, Fu J-D, Delgado-Olguin P, Vedantham V, Hayashi Y, Bruneau BG, et al. Direct reprogramming of fibroblasts into functional cardiomyocytes by defined factors. Cell. 2010;142:375-86.

6. Cao N, Huang Y, Zheng J, Spencer CI, Zhang Y, Fu J-D, et al. Conversion of human fibroblasts into functional cardiomyocytes by small molecules. Science. 2016;352:1216-20.
7. Gyöngyösi M, Haller PM, Blake DJ, Martin Rendon E. Meta-analysis of cell therapy studies in heart failure and acute myocardial infarction. Circ Res. 2018;123:301-8.

8. Giatsidis G, Cheng L, Haddad A, Ji K, Succar J, Lancerotto L, et al. Noninvasive induction of angiogenesis in tissues by external suction: sequential optimization for use in reconstructive surgery. Angiogenesis. 2018;21:61-78.

9. Veith AP, Henderson K, Spencer A, Sligar AD, Baker AB. Therapeutic strategies for enhancing angiogenesis in wound healing. Adv Drug Deliv Rev. 2019;146: 97-125.

10. Ko SH, Bandyk DF. Therapeutic angiogenesis for critical limb ischemia. Semin Vasc Surg. 2014;27:23-31.

11. Kaminsky SM, Rosengart TK, Rosenberg J, Chiuchiolo MJ, Van de Graaf B, Sondhi D, et al. Gene therapy to stimulate angiogenesis to treat diffuse coronary artery disease. Hum Gene Ther. 2013;24:948-63.

12. Groenewegen A, Rutten FH, Mosterd A, Hoes AW. Epidemiology of heart fail ure. Eur J Heart Fail. 2020;22:1342-56.

13. Bozkurt B, Aguilar D, Deswal A, Dunbar SB, Francis GS, Horwich T, et al Contributory risk and management of comorbidities of hypertension, obesity, diabetes mellitus, hyperlipidemia, and metabolic syndrome in chronic heart failure: a scientific statement from the American Heart Association. Circulation. 2016;134:e535-78.

14. Sidney S, Go AS, Jaffe MG, Solomon MD, Ambrosy AP, Rana JS. Association between aging of the US population and heart disease mortality from 2011 to 2017. JAMA Cardiol. 2019;4:1280-6.

15. Truby LK, Rogers JG. Advanced heart failure: epidemiology, diagnosis, and therapeutic approaches. JACC Hear Fail. 2020;8:523-36.

16. Miller L, Birks E, Guglin M, Lamba H, Frazier OH. Use of ventricular assist devices and heart transplantation for advanced heart failure. Circ Res. 2019;124:1658-78.

17. Toma C, Pittenger MF, Cahill KS, Byrne BJ, Kessler PD. Human mesenchymal stem cells differentiate to a cardiomyocyte phenotype in the adult murine heart Circulation. 2002;105:93-8.

18. Gyöngyösi M, Blanco J, Marian T, Tron L, Petnehazy O, Petrasi Z, et al. Serial noninvasive in vivo positron emission tomographic tracking of percutaneously intramyocardially injected autologous porcine mesenchymal stem cells modified for transgene reporter gene expression. Circ Cardiovasc Imaging. 2008;1:94-103.

19. Sanganalmath SK, Bolli R. Cell therapy for heart failure. Circ Res. 2013;113: 810-34.

20. Gnecchi M, Zhang Z, Ni A, Dzau VJ. Paracrine mechanisms in adult stem cell signaling and therapy. Circ Res. 2008;103:1204-19.

21. Nguyen PK, Rhee JW, Wu JC. Adult stem cell therapy and heart failure, 2000 to 2016. JAMA Cardiol. 2016;1:831.

22. Rincon MY, VandenDriessche T, Chuah MK. Gene therapy for cardiovascular disease: advances in vector development, targeting, and delivery for clinical translation. Cardiovasc Res. 2015;108:4-20.

23. Leach JP, Martin JF. Cardiomyocyte proliferation for therapeutic regeneration. Curr Cardiol Rep. 2018;20:1-8.

24. Rosengart TK, Patel V, Sellke FW. Cardiac stem cell trials and the new world of cellular reprogramming: time to move on. J Thorac Cardiovasc Surg. 2018;155: 1642-6.

25. Sainsbury PA, Fisher M, De Silva R. Alternative interventions for refractory angina. Heart. 2017;103:1911-22.

26. Henry TD, Satran D, Hodges JS, Johnson RK, Poulose AK, Campbell AR, et al Long-term survival in patients with refractory angina. Eur Heart J. 2013;34 2683-8.

27. Lanza GA, Crea F. Primary coronary microvascular dysfunction: clinical presentation, pathophysiology, and management. Circulation. 2010;121:2317-25.

28. Kiernan TJ, Boilson BA, Sandhu GS, Lennon RJ, Roger VL, Barsness GW, et al. Nonrevascularizable coronary artery disease following coronary artery bypass graft surgery: a population-based study in Olmsted County, Minnesota. Coron Artery Dis. 2009;20:106-11.

29. Riley RF, Kereiakes DJ, Henry TD. More data than options for the "no-option" refractory angina patient in the United States. Circ Res. 2019;124:1689-91.

30. Mukherjee D, Bhatt DL, Roe MT, Patel V, Ellis SG. Direct myocardial revascularization and angiogenesis - how many patients might be eligible? Am J Cardiol. 1999;84:598-600.

31. Garcia S, Sandoval Y, Roukoz H, Adabag S, Canoniero M, Yannopoulos D, et al Outcomes after complete versus incomplete revascularization of patients with multivessel coronary artery disease: a meta-analysis of 89,883 patients enrolled in randomized clinical trials and observational studies. J Am Coll Cardiol. 2013; 62:1421-31. 
32. Leviner DB, Torregrossa G, Puskas JD. Incomplete revascularization: what the surgeon needs to know. Ann Cardiothorac Surg. 2018;7:463-9.

33. Hattler B, Carr BM, Messenger J, Spertus J, Ebrahimi R, Bishawi M, et al. Clinical and angiographic predictors of patient-reported angina 1 year after coronary artery bypass graft surgery. Circ Cardiovasc Qual Outcomes. 2019;12:1-7.

34. Hattler B, Grover FL, Wagner T, Hawkins RB, Quin JA, Collins JF, et al. Incidence and prognostic impact of incomplete revascularization documented by coronary angiography 1 year after coronary artery bypass grafting. Am J Cardiol. 2020;131:7-11.

35. Bhatt AB, Stone PH. Current strategies for the prevention of angina in patients with stable coronary artery disease. Curr Opin Cardiol. 2006;21:492-502.

36. Mathison M, Singh VP, Chiuchiolo MJ, Sanagasetti D, Mao Y, Patel VB, et al. In situ reprogramming to transdifferentiate fibroblasts into cardiomyocytes using adenoviral vectors: implications for clinical myocardial regeneration. $J$ Thorac Cardiovasc Surg. 2017;153:329-39.e3.

37. Patel V, Singh VP, Pinnamaneni JP, Sanagasetti D, Olive J, Mathison M, et al. p63 silencing induces reprogramming of cardiac fibroblasts into cardiomyocyte-like cells. J Thorac Cardiovasc Surg. 2018;156:556-65.e1.

38. Zhou Y, Liu Z, Welch JD, Gao X, Wang L, Garbutt T, et al. Single-cell transcriptomic analyses of cell fate transitions during human cardiac reprogramming. Cell Stem Cell. 2019;25:149-64.e9.

39. Fu J-D, Stone NRR, Liu L, Spencer CI, Qian L, Hayashi Y, et al. Direct reprogramming of human fibroblasts toward a cardiomyocyte-like state. Stem Cell Rep. 2013;1:235-47.

40. Nam Y-JJ, Song K, Luo X, Daniel E, Lambeth K, West K, et al. Reprogramming of human fibroblasts toward a cardiac fate. Proc Natl Acad Sci U S A. 2013;110: 5588-93.

41. Chira S, Jackson CS, Oprea I, Ozturk F, Pepper MS, Diaconu I, et al. Progresses towards safe and efficient gene therapy vectors. Oncotarget. 2015;6:30675-703.

42. Zhao Y, Londono P, Cao Y, Sharpe EJ, Proenza C, O'Rourke R, et al. High-efficiency reprogramming of fibroblasts into cardiomyocytes requires suppression of pro-fibrotic signalling. Nat Commun. 2015;6:8243.

43. Yamakawa H, Muraoka N, Miyamoto K, Sadahiro T, Isomi M, Haginiwa S, et al. Fibroblast growth factors and vascular endothelial growth factor promote cardiac reprogramming under defined conditions. Stem Cell Rep. 2015;5:1128-42.

44. Mohamed TMA, Stone NR, Berry EC, Radzinsky E, Huang Y, Pratt K, et al. Chemical enhancement of in vitro and in vivo direct cardiac reprogramming. Circulation. 2017;135:978-95.

45. Muraoka N, Nara K, Tamura F, Kojima H, Yamakawa H, Sadahiro T, et al. Role of cyclooxygenase-2-mediated prostaglandin E2-prostaglandin E receptor 4 signaling in cardiac reprogramming. Nat Commun. 2019;10:674.

46. Singh VP, Pinnamaneni JP, Pugazenthi A, Sanagasetti D, Mathison M, Wang K, et al. Enhanced generation of induced cardiomyocytes using a small-molecule cocktail to overcome barriers to cardiac cellular reprogramming. J Am Heart Assoc. 2020;9:e015686.

47. Frantz S, Falcao-Pires I, Balligand JL, Bauersachs J, Brutsaert D, Ciccarelli M, et al. The innate immune system in chronic cardiomyopathy: a European Society of Cardiology (ESC) scientific statement from the working group on myocardial function of the ESC. Eur J Heart Fail. 2018;20:445-59.

48. Singh VP, Mathison M, Patel V, Sanagasetti D, Gibson BW, Yang J, et al. MiR590 promotes transdifferentiation of porcine and human fibroblasts toward a cardiomyocyte-like fate by directly repressing specificity protein 1. J Am Heart Assoc. 2016;5:e003922.

49. Stone NR, Gifford CA, Thomas R, Pratt KJB, Samse-Knapp K, Mohamed TMA, et al. Context-specific transcription factor functions regulate epigenomic and transcriptional dynamics during cardiac reprogramming. Cell Stem Cell. 2019; 25:87-102.e9.

50. Onder TT, Kara N, Cherry A, Sinha AU, Zhu N, Bernt KM, et al. Chromatinmodifying enzymes as modulators of reprogramming. Nature. 2012;483: 598-602.

51. Christoforou N, Chellappan M, Adler AF, Kirkton RD, Wu T, Addis RC, et al. Transcription factors MYOCD, SRF, Mesp1 and SMARCD3 enhance the cardio-inducing effect of GATA4, TBX5, and MEF2C during direct cellular reprogramming. PLoS One. 2013;8:e63577.

52. Dal-Pra S, Hodgkinson CP, Mirotsou M, Kirste I, Dzau VJ. Demethylation of $\mathrm{H} 3 \mathrm{~K} 27$ is essential for the induction of direct cardiac reprogramming by miR combo. Circ Res. 2017; 120:1403.

53. Zhou Y, Wang L, Vaseghi HRR, Liu Z, Lu R, Alihohamadi S, et al. Bmil is a key epigenetic barrier to direct cardiac reprogramming. Cell Stem Cell. 2016;18: 382-95.
54. Kopljar I, Gallacher DJ, De Bondt A, Cougnaud L, Vlaminckx E, Van der Wyngaert I, et al. Functional and transcriptional characterization of histone deacetylase inhibitor-mediated cardiac adverse effects in human induced pluripotent stem cell-derived cardiomyocytes. Stem Cells Transl Med. 2016;5:602-12.

55. Bush EW, McKinsey TA. Protein acetylation in the cardiorenal axis: the promise of histone deacetylase inhibitors. Circ Res. 2010;106:272-84.

56. Mathison M, Singh VP, Sanagasetti D, Yang L, Pinnmaneni JP, Yang J, et al. Cardiac reprogramming factor Gata4 reduces postinfarct cardiac fibrosis through direct repression of the profibrotic mediator snail. J Thorac Cardiovasc Surg. 2017; 154:1601-10.e3.

57. Miyamoto K, Akiyama M, Tamura F, Isomi M, Yamakawa H, Sadahiro T, et al. Direct in vivo reprogramming with sendai virus vectors improves cardiac function after myocardial infarction. Cell Stem Cell. 2018;22:91-103.e5.

58. Qian L, Huang Y, Spencer CI, Foley A, Vedantham V, Liu L, et al. In vivo reprogramming of murine cardiac fibroblasts into induced cardiomyocytes. Nature. 2012;485:593-8.

59. Silva KAS, Emter CA. Large animal models of heart failure. JACC Basic Transl Sci. 2020;5:840-56.

60. Richardson WJ, Clarke SA, Quinn TA, Holmes JW. Physiological implications of myocardial scar structure. Compr Physiol. 2015;4:1877-909.

61. Leotta E, Patejunas G, Murphy G, Szokol J, McGregor L, Cabray JA, et al. Gene therapy with adenovirus-mediated myocardial transfer of vascular endothelial growth factor 121 improves cardiac performance in a pacing model of congestive heart failure. J Thorac Cardiovasc Surg. 2002;123:1101-13.

62. Lindsey ML, Bolli R, Canty JM Jr, Du XJ, Frangogiannis NG, Frantz S, et al. Guidelines for experimental models of myocardial ischemia and infarction. Am J Physiol Heart Circ Physiol. 2018;314:H812-38.

63. Bushman FD. Retroviral insertional mutagenesis in humans: evidence for four genetic mechanisms promoting expansion of cell clones. Mol Ther. 2020;28: 352-6.

64. Yoo SY, Jeong SN, Kang JI, Lee SW. Chimeric adeno-associated virus-mediated cardiovascular reprogramming for ischemic heart disease. ACS Omega. 2018;3: 5918-25.

65. Patel VB, Ryan CT, Crystal RG, Rosengart TK. Gene therapy for coronary artery disease. In: Raja SG, ed. Cardiac Surgery: A Complete Guide. Cham: Springer International Publishing; 2020:269-75.

66. Benskey MJ, Sandoval IM, Miller K, Sellnow RL, Gezer A, Kuhn NC, et al. Basic concepts in viral vector-mediated gene therapy. Methods Mol Biol. 2019; 1937:3-26.

67. Traupe T, Gloekler S, De Marchi SF, Werner GS, Seiler C. Assessment of the human coronary collateral circulation. Circulation. 2010;122:1210-20.

68. Seiler C, Stoller M, Pitt B, Meier P. The human coronary collateral circulation: development and clinical importance. Eur Heart J. 2013;34:2674-82.

69. Jamaiyar A, Juguilon C, Dong F, Cumpston D, Enrick M, Chilian WM, et al. Cardioprotection during ischemia by coronary collateral growth. Am J Physiol Heart Circ Physiol. 2019;316:H1-9.

70. Yuan R, Xin Q, Shi W, Liu W, Lee SM, Hoi P, et al. Vascular endothelial growth factor gene transfer therapy for coronary artery disease: a systematic review and meta-analysis. Cardiovasc Ther. 2018;36:e12461.

71. Hargrave B, Strange R, Navare S, Stratton M, Burcus N, Murray L, et al. Gene electro transfer of plasmid encoding vascular endothelial growth factor for enhanced expression and perfusion in the ischemic swine heart. PLOS One. 2014:9:1-23.

72. Greenberg B, Butler J, Felker GM, Ponikowski P, Voors AA, Desai AS, et al. Calcium upregulation by percutaneous administration of gene therapy in patients with cardiac disease (CUPID 2): a randomised, multinational, double-blind, placebo-controlled, phase 2b trial. Lancet. 2016;387:1178-86.

73. Magovern CJ, Mack CA, Zhang J, Hahn RT, Ko W, Isom OW, et al. Direct in vivo gene transfer to canine myocardium using a replication-deficient adenovirus vector. Ann Thorac Surg. 1996;62:425-34.

74. Mühlhauser J, Jones M, Yamada I, Cirielli C, Lemarchand P, Gloe TR, et al. Safety and efficacy of in vivo gene transfer into the porcine heart with replication-deficient, recombinant adenovirus vectors. Gene Ther. 1996;3: 145-53.

75. Raval AN, Pepine CJ. Clinical safety profile of transendocardial catheter injection systems: a plea for uniform reporting. Cardiovasc Revasc Med. 2021;22: $100-8$.

76. Dib N, Menasche P, Bartunek JJ, Zeiher AM, Terzic A, Chronos NA, et al. Recommendations for successful training on methods of delivery of biologics for cardiac regeneration. A report of the International Society for Cardiovascular Translational Research. JACC Cardiovasc Interv. 2010:3:265-75. 
77. Perin EC, Silva GV, Willerson JT. Training on the use of transendocardial delivery of biologics for cardiac regeneration. JACC Cardiovasc Interv. 2010;3:991.

78. Fargnoli AS, Katz MG, Williams RD, Margulies KB, Bridges CR. A needleless liquid jet injection delivery method for cardiac gene therapy: a comparative evaluation versus standard routes of delivery reveals enhanced therapeutic retention and cardiac specific gene expression. J Cardiovasc Transl Res. 2014;7:756-67.

79. Rosengart TK, Lee LY, Patel SR, Sanborn TA, Parikh M, Bergman GW, et al. Angiogenesis gene therapy: phase I assessment of direct intramyocardial administration of an adenovirus vector expressing VEGF121 cDNA to individuals with clinically significant severe coronary artery disease. Circulation. 1999;100: 468-74.

80. Rosengart TK, Bishawi MM, Halbreiner MS, Fakhoury M, Finnin E, Hollmann C, et al. Long-term follow-up assessment of a phase 1 trial of angiogenic gene therapy using direct intramyocardial administration of an adenoviral vector expressing the VEGF121 cDNA for the treatment of diffuse coronary artery disease. Hum Gene Ther. 2013;24:203-8.

81. Henry TD, Schaer GL, Traverse JH, Posvic TJ, Davidson C, Lee JS, et al. Autologous CD34+ cell therapy for refractory angina: 2-year outcomes from the ACT34-CMI study. Cell Transplant. 2016;25:1701-11.

82. Hedman M, Muona K, Hedman A, Kivela A, Syvanne M, Eranen J, et al. Eightyear safety follow-up of coronary artery disease patients after local intracoronary VEGF gene transfer. Gene Ther. 2009;16:629-34.

83. Whitlock PR, Hackett NR, Leopold PL, Rosengart TK, Crystal RG. Adenovirusmediated transfer of a minigene expressing multiple isoforms of VEGF is more effective at inducing angiogenesis than comparable vectors expressing individual VEGF cDNAs. Mol Ther. 2004;9:67-75.

84. Amano H, Hackett NR, Kaner RJ, Whitlock P, Rosengart TK, Crystal RG. Alteration of splicing signals in a genomic/cDNA hybrid VEGF gene to modify the ratio of expressed VEGF isoforms enhances safety of angiogenic gene therapy. Mol Ther. 2005;12:716-24.
85. Rutanen J, Rissanen TT, Markkanen JE, Gruchala M, Silvennoinen P, Kivela A et al. Adenoviral catheter-mediated intramyocardial gene transfer using the mature form of vascular endothelial growth factor-D induces transmural angiogenesis in porcine heart. Circulation. 2004;109:1029-35.

86. Toivanen PI, Nieminen T, Viitanen L, Alitalo A, Roschier M, Jauhiainen S, et al. Novel vascular endothelial growth factor D variants with increased biological activity. J Biol Chem. 2009;284:16037-48.

87. Jauhiainen S, Häkkinen SK, Toivanen PI, Heinonen SE, Jyrkkanen HK Kansanen E, et al. Vascular endothelial growth factor (VEGF)-D stimulates VEGF-A, stanniocalcin-1, and neuropilin-2 and has potent angiogenic effects. Arterioscler Thromb Vasc Biol. 2011;31:1617-24.

88. Hartikainen J, Hassinen I, Hedman A, Kivela A, Saraste A, Knuuti J, et al Adenoviral intramyocardial VEGF-DDNDC gene transfer increasesmyocardial perfusion reserve in refractory angina patients: a phase I/IIa study with 1-year follow-up. Eur Heart J. 2017;38:2547-55.

89. Hirai T, Aaron Grantham J, Sapontis J, Cohen DJ, Marso SP, Lombardi W, et al Quality of life changes after chronic total occlusion angioplasty in patients with baseline refractory angina. Circ Cardiovasc Interv. 2019;12:1-8.

90. Goodlin SJ, Wingate S, Albert NM, Pressler SJ, Houser J, Kwon J, et al. Investigating pain in heart failure patients: the pain assessment, incidence, and nature in heart failure (PAIN-HF) study. J Card Fail. 2012;18:776-83.

91. Mathison M, Gersch RP, Nasser A, Lilo S, Korman M, Fourman M, et al. In vivo cardiac cellular reprogramming efficacy is enhanced by angiogenic preconditioning of the infarcted myocardium with vascular endothelial growth factor. J Am Heart Assoc. 2012;1:e05652.

Key Words: ischemic heart disease, angiogenesis, cellular reprogramming, gene therapy, regenerative medicine 